\title{
ANÁLISE DE FALHAS NO PROCESSO LOGÍSTICO DEVIDO A FALTA DE UM CONTROLE DE QUALIDADE
}

\section{ANALISYS OF FLAWS IN TO LOGISTIC PROCESS JUST THE NECESSITY OF A QUALITY CONTROL}

\author{
Juliana Menna Barreto \\ UFSM - Universidade Federal de Santa Maria \\ PPGEP - Programa de Pós-Graduação de Engenharia de Produção \\ (54) 9144-9840; jucomex@annex.com.br \\ Luis Felipe Dias Lopes \\ UFSM - Universidade Federal de Santa Maria \\ PPGEP - Programa de Pós-Graduação de Engenharia de Produção
}

(55) 99718584; phil.zaz@zaz.com.br

\begin{abstract}
RESUMO
É comum que, no Sistema Logístico, ocorram falhas que podem ser resultantes de variáveis internas e/ou externas à empresa. Os clientes esperam receber produtos em conformidade com o prometido no que se refere à qualidade, cor, boas condições, quantidade do produto. Ao receberem um produto com características avariadas todo esforço despendido pela empresa foi em vão. Uma maneira de amenizar esses danos aos produtos consiste na aplicação da Gestão da Qualidade Total (TQM) e suas ferramentas. Pelo TQM, é possível diagnosticar os fatores que estão em desacordo com o que fora traçado, avaliando a situação da nãoconformidade dos produtos. A aplicação das Ferramentas da Qualidade Total como o Diagrama de Ishikawa e o Ciclo PDCA foram possíveis detectar os processos que possuem falhas, permitindo a correção. Com essas implantações, os resultados se darão em médio prazo, porém as empresas potencializarão seu diferencial competitivo ao entregarem produtos com baixo índice de avarias. Através de comparações entre duas empresas do ramo moveleiro, foi possível detectar falhas no sistema logístico, para o qual foi sugerida e implantada o Controle de Qualidade, auxiliado pelas ferramentas da Qualidade com o objetivo principal de minimizar os custos decorrentes de danificações de produtos das empresas em estudo.
\end{abstract}

Palavras-chaves: Ferramentas da qualidade, produtos danificados, sistema logístico.

\begin{abstract}
It is common that, in the Logistic System, flaws that can be resulting of internal variables happen and/or outside to the company. The customers hope to receive the products in
\end{abstract}


accordance with the promised, in other words, products without defects in the aspects that refer to the quality, color, good conditions, amount of the product. In the receive a product with averaged characteristics all effort spent for the company was in vain. A way to soften all those damages to the products consists of the application of the Total Quality Management (TQM) and their tools. Through TQM, it is possible to diagnose the factors that are in disagreement with what had been drawn in order to best to evaluate the situation of the noconformity of the products. The apply Tools of the Total Quality as Diagram of Ishikawa and Cycle PDCA went possible to detect the processes that possess flaws, allowing the correction. Starting from those implantations in the process logistic, the results are watching a medium period, however the companies will be powerful her differential one competitive they give to products with low index of mishaps. Through comparisons among two companies of the branch of the furniture, it was possible to detect fail in the logistic system, for which was suggested and implant the Quality control, aided by the tools of the Quality in order to minimize the current costs of corruptions of the products of the companies in study.

Key-Words : Tools of the quality, damaged products, system logistic.

\section{INTRODUÇÃO}

Apesar de já existir forte competitividade entre as empresas, até a algum tempo atrás, não se dava tanta importância em empregar um diferencial que fosse lhes dar sustentabilidade, a fim de atender as necessidades dos clientes. Atualmente, essa abordagem mudou. Investimento, flexibilidade, adaptação, estratégia, comunicação, aperfeiçoamento continuado são algumas das atitudes atuais pertinentes pelos gestores nas empresas, objetivando agregar valor aos seus produtos, serviços e à própria organização.

Neste âmbito, a logística também preza por planejamento e adequação por parte da empresa para melhor satisfazer os consumidores. Em síntese, esse é o aspecto que caracteriza a missão de todo o processo logístico: a satisfação dos clientes com o produto certo, no lugar certo, no momento também correto, com o menor custo possível. Para que a missão logística se concretize de fato, é primordial aplicar recursos com a finalidade de que o processo logístico seja capaz de realizar as atividades de movimentação dos produtos sem que haja qualquer tipo de danos nos bens transportados.

Porém, sabe-se que, na realidade, a intenção acima nem sempre é atingida. Isso se deve ao fato de que muitas organizações ainda não estão adaptadas para desenvolver uma entrega perfeita, com zero defeito. No entanto, ao conciliarem o processo de movimentação de produtos com a Gestão e as Ferramentas da Qualidade Total, o resultado reverterá em produtos com qualidade superior. No momento em que essa qualidade superior for percebida pelos consumidores tanto a organização como a logística alcançarão seu maior objetivo: satisfazer plenamente as necessidades e os desejos dos seus clientes com a entrega de produtos com qualidade. 
Este estudo tem como objetivo principal analisar as possíveis falhas num sistema logístico que poderão ocorrer em função da falta de aplicação das ferramentas da Qualidade Total no processo. Esta pesquisa visou encontrar a resposta para a seguinte pergunta: quais são os fatores ligados ao processo logístico, responsáveis pelo resultado em falhas nesse processo?

Para a investigação do estudo utilizourse como técnica de pesquisa para coletar dados por meio de aplicação de entrevista a alguns colaboradores das empresas moveleiras em estudo no interior do Rio Grande do Sul. Após a coleta de dados e a observação nas empresas, elaborou-se sugestões para que as mesmas pudessem aplicar para otimizar o seu processo logístico, permitindo a diminuição do índice de avarias nos produtos.

\section{CENÁRIOS TURBULENTOS E INCERTOS QUE CARACTERIZAMO}

\section{SÉCULO XXI}

As empresas do século XXI estão inseridas em um ambiente caracterizado por constantes transformações rápidas e mais amplas por se tratarem de mudanças que envolvem o mundo inteiro. Essas mudanças repercutem em efeitos instantâneos, na maioria das vezes, nas organizações e nas estratégias administrativas. Caracterizado pela inexistência de fronteiras, o cenário atual, apresenta intensa competição econômica e de negócios nos ditos mercados globais. A velocidade de mudança é intensa. Cabe aos gestores aproveitarem essa aceleração tecnológica e de informação para as aplicarem em fatores de diferenciação nos mercados em que atuam.

Não há dúvidas de que o ambiente influencia diretamente uma empresa. De igual forma, influências tecnológicas, econômicas, físicas, sociais e políticas são extremamente relevantes ao se tomar uma decisão estratégica. As mudanças no ambiente empresarial precisam de monitoramento contínuo para que a organização se adapte às transformações, evitando-se tornar obsoleta, mas sim tornar-se competitiva por atender, de forma satisfatória, os desejos e as necessidades dos clientes.

Para Stoner \& Freeman (1999, p. 48), "as coisas que a organização traz do ambiente e o que ela faz com as mesmas - irão determinar a qualidade e o preço de seu produto final".

Para que uma empresa prospere em um cenário conturbado, onde prevalece a inconstância na economia, na política e na cultura, os gestores devem saber aliar a disponibilidade dos recursos com o cumprimento das metas e dos objetivos traçados pela organização. De qualquer modo, não se pode ignorar, nesse cenário, o papel do acaso, ou seja, fatos que acontecem e que nem sempre estavam previstos na maioria das empresas. Isso determina organizações e gestores pró-ativos, ou seja, aqueles que se antecipam aos 
acontecimentos inesperados e que, através dessa antecipação, conseguem tirar proveitos e benefícios desses acontecimentos.

Porter (1989a, p. 89) comenta que "tais acontecimentos criam descontinuidade que podem descongelar ou remodelar a estrutura da indústria e proporcionam oportunidades para que as empresas de um país suplantem as de outro”.

Porém, não basta que os administradores sejam apenas flexíveis e pró-ativos, eles devem igualmente obter informações acerca da empresa, pois quanto mais informado não só da empresa, mas também das tendências do mercado, melhor será a eficácia das decisões e dos planos almejados. Dessa forma, segundo Mintzberg \& Quinn (2001, p. 37), “assim, o banco de dados estratégico da organização não está na memória dos computadores, mas na cabeça dos gerentes".

Dois outros fatores essenciais para o administrador e sua equipe de trabalho que deseja sucesso no mercado concentram-se na criatividade e na inovação. Uma empresa que preza diferenciação e qualidade no atendimento e nos produtos e serviços oferecidos aos clientes poderá conquistar a liderança de mercado consumidor, além de atingir os propósitos organizacionais.

Segundo o pensamento de Pree (2001), as pessoas criativas permanecem afastadas do restante das outras pessoas. De qualquer maneira, a contribuição dada à empresa por pessoas criativas e inovadoras afeta grande parte dos grupos e move as organizações a atingir coisas melhores.

Todavia, é comum às empresas não aplicarem as sugestões criativas dos seus colaboradores, apesar de haver incentivos para tal. De acordo com Hamel, (2003), isso acontece devido aos líderes não terem um modelo desenvolvido do que gostariam que se inovasse na organização. A falta de um modelo acarreta o desconhecimento para as pessoas do que irão construir.

Atualmente, é uma realidade e uma tendência empresas inter-relacionarem-se com outras empresas, sejam fornecedores, clientes e até concorrentes, como forma estratégica de se tornarem mais fortes e reconhecidas no mercado. Essa atitude é uma maneira de quebrar barreiras e romper paradigmas com relação à concorrência, tornando o mercado mais próximo dos compradores através do compartilhamento de atividades entre empresas do mesmo ramo. Isso acaba resultando em vantagem competitiva para as empresas, uma vez que ficarão mais fortes inter-relacionadas do que se estivessem operando isoladamente.

Portanto, para que uma empresa se torne verdadeiramente competitiva, ela deverá aumentar a sua produtividade ao mesmo tempo em que deverá melhorar a qualidade dos seus 
produtos, apurando a tecnologia ou então intensificando a eficiência da sua produção. Salienta-se que uma empresa competitiva não é aquela que possui mão-de-obra barata ou opera com taxas de câmbio favoráveis: a competitividade está diretamente relacionada com qualidade e produtividade dos produtos e serviços disponíveis aos compradores.

Uma empresa torna-se verdadeiramente competitiva quando consegue criar um valor para seus clientes, ou seja, o valor que os mesmos estão dispostos a pagar naquele momento por determinado produto ou serviço. Esse valor pode surgir tanto de custos mais baixos do que a concorrência quanto da diferenciação em um ou mais aspectos ofertados.

Conforme o pensamento de Porter (1989b, p. 111), "uma empresa diferencia-se da concorrência se puder ser singular em alguma coisa valiosa para os compradores. A diferenciação é um dos dois tipos de vantagem competitiva de que uma empresa pode dispor".

\section{GERINDO ESTRATÉgIA LOGÍSTICA PARA OBTER COMPETÊNCIA}

\section{INTEGRADA}

Um gerenciamento eficiente do sistema logístico pode proporcionar à organização uma fonte de vantagem competitiva, a qual poderá ocupar uma posição superior que seja duradoura frente aos demais concorrentes no que se concerne à preferência dos clientes por determinada empresa. Assim, todo o esforço despendido pelos colaboradores no processo logístico trará resultados positivos à organização.

Bowersox \& Closs (2001, p. 21) comentam que, apresentando desempenho acima da média em termos de disponibilidade de estoque e velocidade e consistência de entrega, as empresas logisticamente sofisticadas passam a ser vistas como fornecedores preferenciais e parceiros ideais.

A Figura 1 esclarece as principais áreas do sistema logístico em que deverá ser realizado planejamento para resolver os possíveis problemas concernentes a essas atividades.

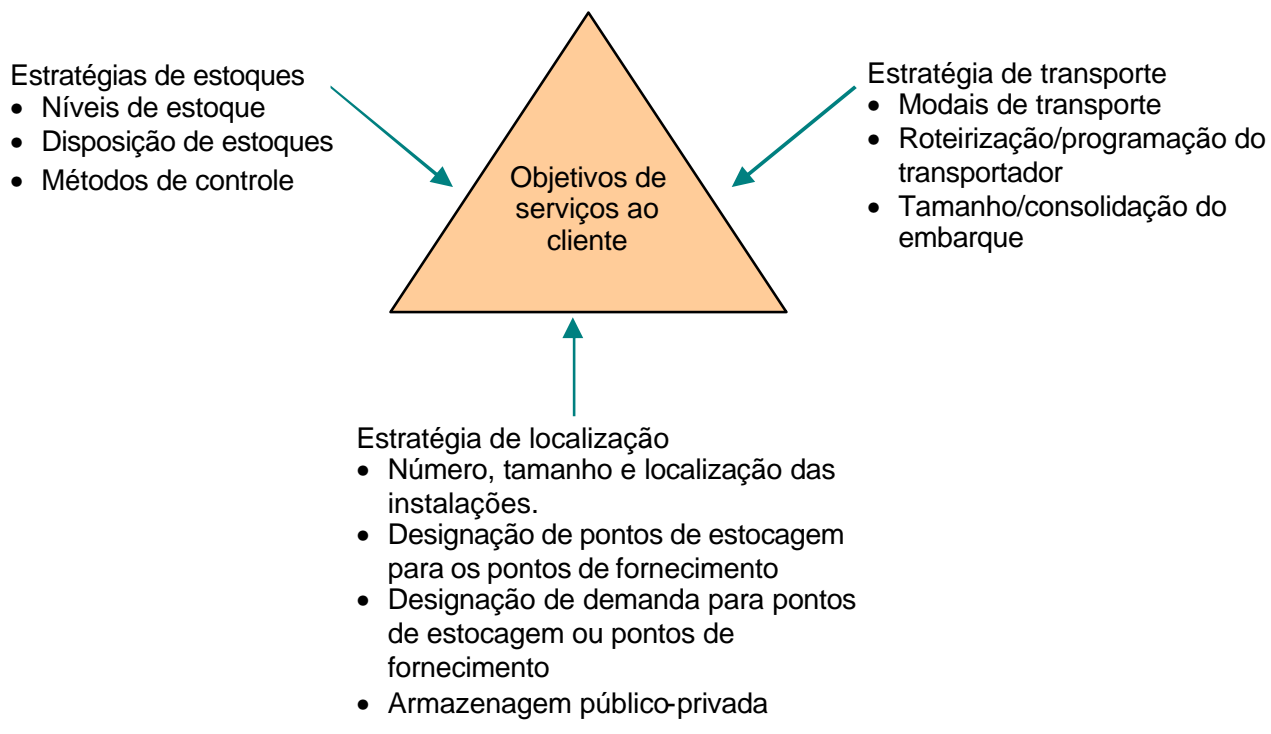


Figura 1: Triângulo da tomada de decisões logísticas

Fonte: Ballou (2001, p. 42).

Essas áreas estão inter-relacionadas, devendo ser planejadas como uma unidade para obter um melhor resultado logístico. Executar planejamento estratégico, tático e operacional se torna vital para a excelência do funcionamento das atividades que a logística engloba.

Bowersox \& Closs (2001, p. 20) afirmam que "dentro da empresa, o desafio é coordenar o conhecimento específico de tarefas individuais numa competência integrada concentrada no atendimento ao cliente".

A localização geográfica tanto dos pontos de estocagem quanto dos pontos de fornecimento dá sustentação para o planejamento logístico. É a localização geográfica que influenciará no aumento ou na redução da demanda dos produtos no mercado. Assim, dependendo da localização, os produtos terão seus custos maximizados ou não, devido aos custos de movimentação desses produtos de um ponto a outro.

O gerenciamento dos estoques também é extremamente importante para um orçamento organizacional, pois os estoques em demasia incorrem em altos custos de mão-de-obra, produtos obsoletos, entre outras conseqüências, o que acaba prejudicando o objetivo maior da logística.

As decisões de transporte acabam envolvendo qual tipo de modal utilizar. Importa ver qual o tamanho do carregamento, qual roteiro e programação adotar para realizar uma movimentação eficaz. Todas essas decisões possuem influência direta da distância entre a armazenagem até os clientes, sendo de responsabilidade dos profissionais logísticos definirem o melhor meio de movimentação dos bens.

Contudo, o real interesse empresarial em programar as atividades logísticas eficientemente não se restringe à redução dos custos, mas consiste, principalmente, em obter vantagem competitiva no momento em que proporciona aos clientes um serviço superior. Isso pode ser conseguido através de um contínuo aperfeiçoamento por parte de toda a organização.

Assim, a responsabilidade operacional da logística está diretamente relacionada à disponibilidade dos insumos, dos produtos semi-acabados e dos estoques de produtos acabados nos locais onde são solicitados, na intenção permanente de realizar a entrega com o menor custo possível, satisfazendo os consumidores.

Finalmente, Bowersox \& Closs (2001, p. 66) concluem que, 
a competência logística é um meio concreto para atrair clientes que valorizam o desempenho em termos de tempo e lugar. Para outros clientes, as dimensões críticas do esforço de marketing podem ser promoção e propaganda ou preço. Independentemente da ênfase das atividades de marketing, o desempenho logístico é parte integrante de todas as estratégias, pois nenhuma transferência de posse pode ocorrer sem o cumprimento das exigências de tempo e lugar.

\subsection{Atendimento logístico do serviço ao cliente: um fator de diferenciação}

No que tange ao sistema logístico, serviço ao cliente significa os resultados de todas as atividades logísticas, em que o próprio sistema estabelece o nível de serviço ao cliente que lhe será oferecido.

De outra parte, enquanto a área de marketing tem o foco centrado em agregar valor ao produto em relação à forma e à transferência de propriedade, a logística enfatiza as necessidades de tempo e lugar. Dessa maneira, a logística assegura a disponibilidade do produto ou serviço no momento e no lugar que o cliente deseja.

Convém salientar que uma empresa, para ter excelência em serviço ao cliente, deverá, fundamentalmente, apresentar três atributos bem aprimorados: disponibilidade, desempenho e confiabilidade do produto/serviço.

A disponibilidade revela-se essencial para um bom serviço ao cliente, uma vez que as empresas devem ter o produto em estoque no exato momento em que ele é desejado. Essa disponibilidade de produtos pode ser conseguida através de previsões das necessidades, incluindo estratégias diferentes para produtos específicos, podendo ser dividido em estoque básico e de segurança. O ideal é haver equilíbrio de estoque de acordo com a previsão de demanda.

De acordo com Christopher (1997, p. 6),

(...) o serviço está relacionado ao processo de desenvolvimento de relações com os clientes através da disponibilidade de uma oferta incrementada. Este incremento pode tomar várias formas, incluindo-se o serviço de entrega, serviço pós-venda, pacotes financeiros, apoio técnico e assim por diante.

O desempenho operacional, por sua vez, envolve comprometimento por parte do sistema logístico com relação ao prazo de execução, bem como com a variação aceitável. Medidas operacionais determinam o desempenho em relação à velocidade, à consistência, à 
flexibilidade e às falhas e recuperação das operações logísticas, avaliando a probabilidade de ocorrer algum imprevisto como avarias nos produtos, em documentos incorretos, entre outros problemas.

Por derradeiro, o atributo confiabilidade logística reflete a qualidade com que a empresa está operando, ou seja, determina o equilíbrio perfeito entre a disponibilidade e o desempenho operacional. Também está relacionado ao fluxo de informações rápidas e precisas aos clientes.

Porém, não basta um sistema logístico possuir as três características acima se não houver um contínuo aperfeiçoamento e aprimoramento das atividades logísticas. Para tal, é necessário realizar avaliações em determinado período de tempo e fazer as devidas modificações necessárias para primar pelo atendimento perfeito desde a primeira vez.

Assim, Ballou (2001, p. 65) comenta que,

quando os clientes encontram pouca ou nenhuma diferença entre o produto da empresa e dos fornecedores concorrentes, diz-se que os produtos são de alta substituibilidade. Isto é, o cliente está prontamente disposto a optar por uma segunda marca quando a primeira não estiver imediatamente disponível.

Indiscutivelmente, o serviço ao cliente cria valor ao produto e, conseqüentemente, à empresa. Nesse sentido, os produtos não possuem valor até o momento em que eles estejam nas mãos dos clientes, na hora e no lugar exigidos. Conseguir mais clientes satisfeitos significa atender as expectativas de mais clientes. Conseguir que grupos específicos de clientes fiquem mais satisfeitos significa focar a atenção nesses grupos com o objetivo de superar suas expectativas e, assim, assegurar que suas compras sejam regulares, caracterizando um relacionamento de longo prazo.

Confirmando o exposto acima, Christopher (1997, p. 17) menciona que "essencialmente, o papel do serviço ao cliente deve ser a melhoria do 'valor do uso', significando, com isso, que o produto passa a ter mais valor aos olhos do cliente, porque o serviço adicionou valor à essência do produto".

\subsection{Avarias: conseqüências negativas aos clientes e às empresas}

A logística preza por desenvolver e realizar suas atividades sem erros desde a primeira vez. O atendimento correto deve iniciar com o recebimento do pedido até a entrega do produto ao cliente final, incluindo todas as atividades sem erros, com zero defeito.

Muitas empresas decidem por arcar com custos adicionais para realizar um atendimento perfeito a apenas um grupo de clientes pré-selecionados, sendo considerados 
atrativos para a empresa. No entanto, o ideal seria praticar atendimento perfeito para a maioria dos clientes, sem distinção de ser cliente preferencial ou não. Assim, um cliente novo, ao receber atendimento perfeito, pode-se tornar um cliente em potencial. Contudo, atendimento perfeito ao cliente incorre em altos custos com tecnologia, treinamento aos colaboradores, entre outros.

Por outro lado, ao receber um produto com defeitos ou com danos, o consumidor imediatamente ficará insatisfeito não só com o produto, mas também com a empresa. E, mesmo que a organização realize a troca ou o conserto de produtos avariados, isso demanda em determinado período de tempo para substituir o produto e retorná-lo de posse do cliente. Atualmente, muitos consumidores não querem esperar ainda mais para desfrutar da compra, o que gera insatisfação dos mesmos e custos adicionais para a empresa. Enfim, para que o sistema logístico realmente atinja os objetivos e, conseqüentemente, os resultados almejados, as atividades logísticas devem estar aliadas à Gestão da Qualidade, além da aplicação das Ferramentas da Qualidade Total tanto nos produtos como nos serviços prestados aos seus clientes.

\section{QUALIDADE TOTAL: UMA FORMA DE SOBREVIVÊNCIA NO} MERCADO COMPETITIVO

Justamente por se estar vivendo em um ambiente onde há, cada vez mais, novas alternativas de empresas e de produtos/serviços de fácil substituibilidade, os consumidores estão mais intolerantes com relação aos produtos e/ou serviços que não apresentam uma qualidade desejável, entregas com atrasos, produtos com avarias, mão-de-obra de má qualidade.

Atualmente, as organizações buscam obter qualidade nos produtos e serviços prestados aos clientes como uma forma de se sobressaírem no mercado, conquistando a excelência em atividades frente aos olhos dos consumidores. Realmente, a qualidade é um fator-chave para que as empresas possam competir não só no mercado interno, mas também no externo, enfrentando grandes organizações de classe mundial com o mesmo enfoque competitivo.

Todavia, todo o esforço das organizações em oferecerem produtos/serviços com qualidade só será realmente eficiente se essa qualidade for percebida, com excelência, pelos próprios consumidores. Reconhecidamente, obter qualidade nos produtos ou serviços incorre com custos, investimentos, sendo que as empresas que não possuem um processo pela busca contínua de qualidade terão maiores gastos com produtos com defeitos, danificados ao substituí-los aos consumidores. Além desse custo adicional em prestar assistência técnica para 
o produto, as empresas acabam tendo uma imagem negativa perante seus clientes, e o fato somente se revelará positivo para a concorrência.

Parte-se da premissa de que as organizações estão no mercado para satisfazer seus clientes e tem-se como conseqüência sua sobrevivência no mercado competitivo. Para que isso se efetive, torna-se necessário que os dirigentes apliquem as ferramentas da qualidade total para obter um controle dos processos e a melhoria dos resultados desses processos.

Desse modo, o objetivo maior de aplicar Controle da Qualidade Total em organizações é, segundo Drummond (1998), fazer com que os clientes percebam que aquela corporação possui comprometimento e envolvimento de todos para que o cliente evidencie as melhorias dos produtos e serviços e delas desfrute.

Cabe salientar que muitos empreendedores aplicam métodos de melhoria objetivando o aumento de lucros em um curto período de tempo. Porém, a aplicação de TQM tem por finalidade a satisfação plena dos clientes e como conseqüência, a empresa obterá lucros e sucesso no mercado em que atua. As empresas que utilizam essa técnica fazem pesquisas para saber o que realmente os clientes precisam, além de conhecerem suas opiniões, pois essa é a principal preocupação da Qualidade: a plena satisfação dos seus clientes.

Em virtude da aplicação do método de Controle de Qualidade Total (TQC), há ferramentas direcionadas para o controle e a melhoria dos processos, denominadas Diagrama de Ishikawa e Ciclo PDCA.

A fim de melhor representar a relação e a sua separação da causa-efeito, existe o Diagrama de Ishikawa, ferramenta de diagnóstico, que também é conhecida por Diagrama espinha de peixe. O Diagrama de Ishikawa foi criado com o objetivo de que os colaboradores das organizações, independentemente do cargo que ocupem, possam separar os fins dos meios dos processos empresariais. O Diagrama de Ishikawa é ilustrado pela Figura 2 .

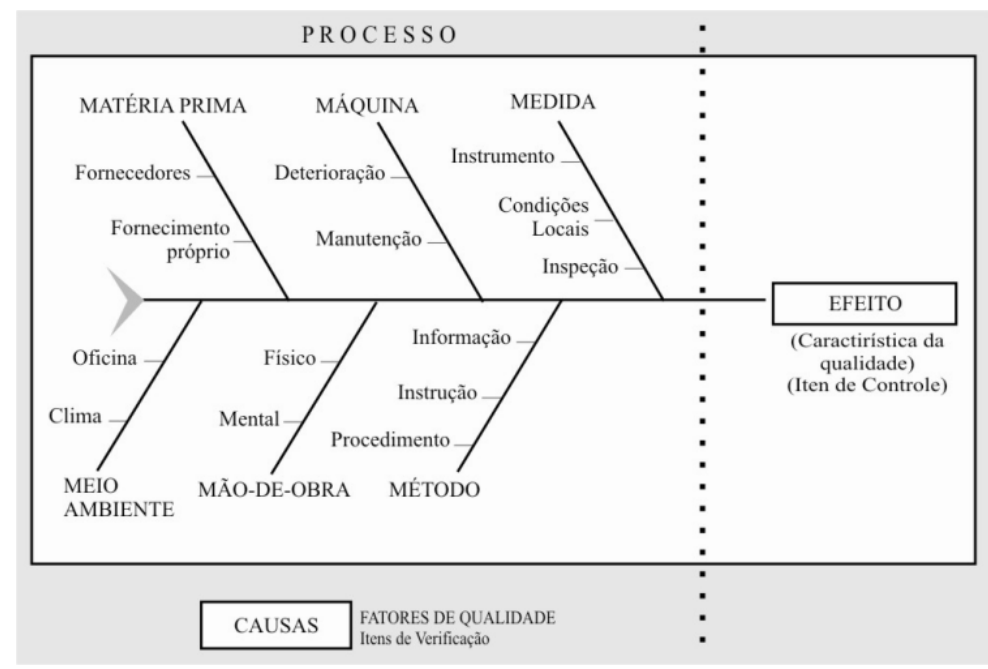


Figura 2: Diagrama de Ishikawa ou Causa e Efeito

Fonte: O autor

Para um melhor gerenciamento da qualidade, convém dividir e subdividir o processo, pois enquanto houver causas e efeitos, haverá processos. Dessa forma, esse gerenciamento irá conduzir para um controle mais eficiente sobre o processo como um todo. Portanto, ao subdividir o processo em processos menores, torna-se mais fácil localizar o problema e agir diretamente sobre sua causa.

Ao identificar o problema da empresa, procurando a causa que o provocou, realiza-se uma análise do processo em questão. Após o término da análise do processo e localizada a causa principal que originou o problema, deve-se realizar um novo procedimento, ou seja, uma padronização de execução do processo. A partir da padronização estabelecida, devem-se instituir os pontos de controle com os itens de controle para se certificar de que os novos procedimentos (padronização) estão sendo seguidos. Portanto, manter, sob controle um processo, é o procedimento de localização do problema, analisando o processo, padronizandoo e estabelecendo-se itens de controle para evitar o problema identificado anteriormente.

O ciclo PDCA, conforme Campos (1992) evidencia-se como um método para a prática de controle da qualidade no que concerne aos processos organizacionais. Esse controle da qualidade é extremamente importante para todas as empresas que pretendem ter um diferencial estratégico para competir com seus concorrentes potenciais no mercado. As letras PDCA significam $P$ (Plan) de planejamento; $D(D o)$ que significa fazer; $C$ (Control) que quer dizer controle e $A$ (Action), ação. Esse método preconiza que todos os processos devem ser continuamente melhorados através de estudos e planejamentos, além de ter suas mudanças implementadas e controladas. Após esses passos, deve-se, por fim, realizar uma avaliação dos resultados obtidos conforme a Figura 3.

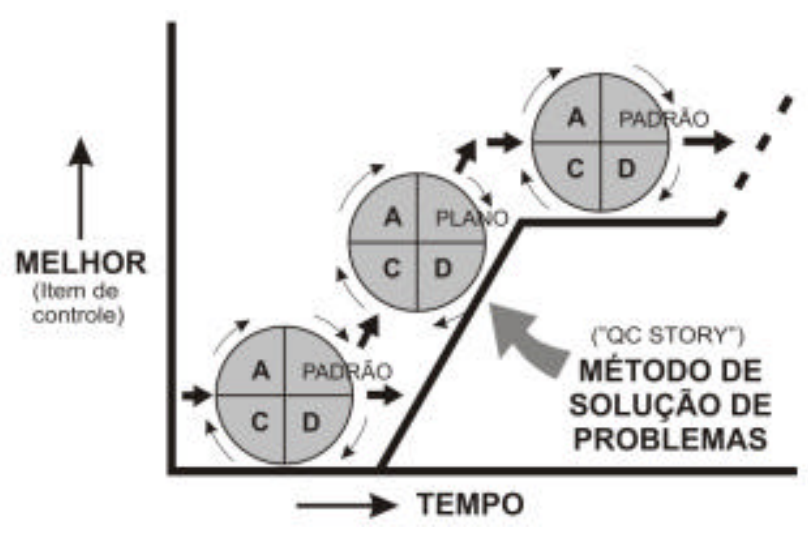


Figura 3: Conceitos de melhoramento contínuo baseado na conjugação dos ciclos PDCA de manutenção e melhorias.

Fonte: Campos (1992, p. 34)

Oliveira (2004, p. 6) menciona que o ciclo PDCA deve:

desenvolver-se de forma contínua e indefinidamente a fim de que depois de idealizado, implantado, medido e tendo estudado os resultados, possa novamente ser utilizado para outra melhoria, permitindo que o processo não se estagne e esteja sempre evoluindo.

Deve-se ter em vista que a utilização de métodos de controle da Qualidade tem por objetivo maior a satisfação plena dos consumidores, através da garantia da qualidade nos produtos ou serviços prestados pela empresa. Garantir qualidade no processo não significa necessariamente garantir a qualidade somente no processo produtivo, mas também em todas as atividades que antecedem a produção, bem como com relação à distribuição dos produtos manufaturados (processo logístico).

\section{PROPOSTA DE APLICAÇÃO DE UM SISTEMA DE QUALIDADE VISANDO AMENIZAR AS AVARIAS DAS INDÚSTRIAS MOVELEIRAS}

Foram realizadas observações de forma comparativa entre duas empresas do ramo moveleiro no interior do Rio Grande do Sul, no qual uma é localizada na região central e outra na região norte do estado, sendo que não foi autorizado utilizar o nome verdadeiro destas.

Assim, convém ressaltar que a empresa da região central possui 31 anos atuando no ramo de móveis, possui aproximadamente 400 funcionários, sendo também atuante no mercado externo. Apesar de ser caracterizada por uma empresa de grande porte e estar preocupada no engajamento de prestar produtos/serviços de qualidade aos consumidores, possui um alto índice de produtos danificados que retornam à fábrica, despendendo um valor numérico significativo.

Já a outra empresa localizada na região norte do Estado, possui 11 anos de funcionamento. Esta demonstra constante preocupação em manter seu quadro de 80 funcionários qualificados, incentivando-os para a atualização profissional, também atuante no mercado internacional e possui igualmente o mesmo problema de retorno de avarias nos móveis.

Através de comparações entre as duas empresas, buscou descobrir quais as principais causas dessa ocorrência para então verificar quais as possíveis atitudes das empresas frente às 
avarias dos produtos. Nesse caso específico, os clientes, em potencial, são atacadistas e, principalmente, varejistas (lojistas).

Foram realizadas análises sobre os itens internos às empresas que poderiam causar danos nas mercadorias e entrevistas com responsáveis pelos setores da Assistência Técnica e Expedição, bem como a apreciação de relatórios mensais de 2004, possibilitando constatar-se que, em relação aos produtos da empresa da região central, os detentores de maior frequiência de sucessões de avarias em termos de números e valores estão: puxadores, espelhos e portas de roupeiros. $\mathrm{Na}$ verdade, há danos em, praticamente, todos os itens, porém uns são mais significativos que outros por haver maior número de peças danificadas que chegam diariamente à Assistência Técnica da fábrica. Com relação à fábrica da região norte, constatou-se que a ocorrência mais significativa de danos acontece, com maior frequiência, em vidros; há falta de peças; existem peças com defeitos e lâminas avariadas que foram devolvidas pelos varejistas à fábrica.

Ao ocorrerem danos, avarias aos produtos e ao serem tais prejuízos percebidos pelos consumidores, todo o esforço despendido pelas organizações terá sido em vão. Mais do que nunca, os clientes exigem qualidade não só em produtos, mas também nas respostas esperadas pelas empresas em resolver seus problemas com relação aos bens ou serviços, incluindo assistência aos mesmos. Devido à grande competitividade entre concorrentes, oferecer um produto ou serviço com qualidade já não é mais um fator de diferenciação: tornourse uma obrigação da empresa frente ao seu consumidor.

O procedimento da produção dos móveis de ambas as fábricas inicia com a chegada da matéria-prima na fábrica, quando é distribuída sob forma de empilhamento, em um espaço destinado para tal. Essas matérias-prima entram no processo de transformação, cujo processo produtivo está composto por máquinas e equipamentos modernos, além de conter todos os cuidados necessários com a segurança dos colaboradores, tais como: máscaras, luvas, protetores de ouvidos. Percebe-se que as fábricas possuem constante preocupação com o investimento em equipamentos adequados para aumentar sua produtividade e acompanhar as tendências do mercado. A verificação de qualquer tipo de desvio na produção é realizada pelos próprios operadores das máquinas, comunicando imediatamente esse fato ao responsável pelo setor.

Após a matéria-prima estar transformada em peças que, ao serem montadas, compõem os móveis, vão então para o processo de embalamento. Nessa etapa, os produtos são embalados desmontados, sendo que cada caixa contém todas as peças necessárias para que o cliente possa montar seu bem. 
Na fábrica da região central, a embalagem é composta por caixas de papelão de gramatura baixa; isomantas para separação das peças dentro das caixas (protege contra riscos e arranhões); para as peças com espelhos, são colocadas ripas de madeiras nas extremidades para proteger os espelhos; cola (para grudar uma extremidade à outra) e cintas plásticas são os itens que compõem a embalagem final.

Já na empresa da região norte, a embalagem também é composta por caixas de papelão, porém com gramatura superior; plástico-bolha para produtos destinados ao mercado externo e plástico comum para separar os produtos para o mercado interno. Os vidros e os espelhos são embalados e protegidos com embalagens de madeira, fabricados na própria fábrica, com as sobras das chapas de compensado. As caixas também são lacradas com cola e cintas plásticas.

Após os produtos estarem embalados, os colaboradores das duas empresas movimentam as embalagens para a expedição através de equipamentos apropriados como paletedeiras automatizadas, carrinhos-de-mão e esteiras rolantes o que contribui para uma movimentação eficaz dentro da fábrica. As embalagens são separadas por pedidos dos clientes.

Os produtos permanecem na expedição aguardando o transporte. $\mathrm{O}$ armazenamento na expedição, assim como o armazenamento de matéria-prima, se dá através de empilhamento vertical em paletes de madeira. Ao chegar o transporte, os produtos, separados por pedidos armazenados na expedição, são novamente movimentados até os caminhões que os levarão até seu destino final. O tempo de armazenagem dos produtos depende da chegada dos caminhões, variando de dias, semanas ou meses.

No entanto, na empresa da região central, não foi realizado nenhum teste para se averiguar, com exatidão, quanto a embalagem adotada e utilizada resiste ao empilhamento. É tão verdadeiro que foi observado que, no processo de expedição, as embalagens inferiores já demonstravam algum tipo de alteração, o que não se constatou na outra empresa em estudo. Isso, provavelmente, deve-se ao fato dela realizar testes de peso para os produtos, respeitando os limites de peso comunicado pelos fornecedores das embalagens.

Existe Assistência Técnica das duas empresas, para a qual é destinado todo produto avariado que chega às fábricas. Na Assistência Técnica, é prestada substituição parcial ou total dos bens, dependendo do tipo de dano existente nos produtos. O tempo médio das fábricas em reposicionarem os produtos danificados varia, em torno de 15 dias, independentemente do local para o qual este novo produto irá ser destinado. 
Com relação aos itens de maior ocorrência de avarias na fábrica da região central, os puxadores estão classificados como o item de maior freqüência de danos, representando uma soma de R \$ 449,72 (US\$ 149,91) ao mês de substituição desse produto por um outro novo. As portas de roupeiros, de um modo geral, indiferentemente de ser roupeiro de casal, solteiro, sem mencionar a linha de dormitório, é o segundo item com maior freqüência em avarias, representando $\mathrm{R} \$ 3.778,42$ (US\$ $1.259,47$ ) e o mais significativo em termos de valores monetários. Já os espelhos somam R \$ 1.315,91 (US\$ 438,64) e as laterais dos roupeiros, R\$ 2.300,00 (US\$ 766,67). A Figura 4 representa os valores em porcentagem dos produtos danificados.

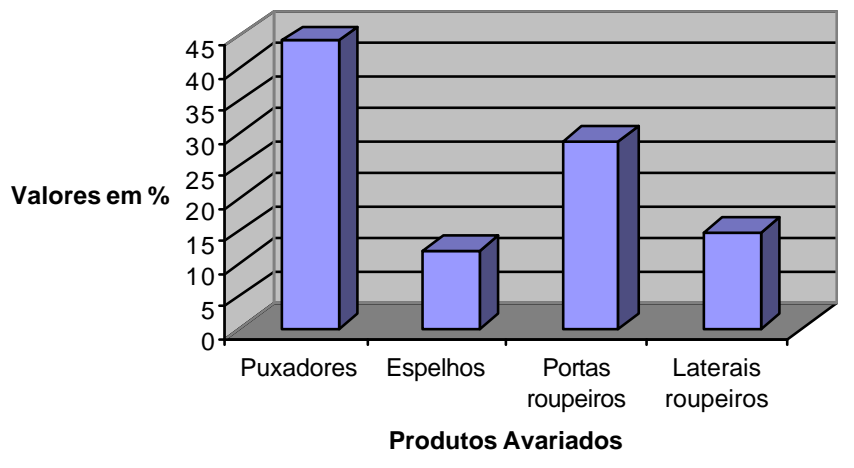

Figura4: Produtos avariados no mês de janeiro de 2004.

Fonte: O autor

Esses itens correspondem aos de maior freqüência a serem encaminhados para a Assistência Técnica da fábrica da região central, perfazendo um universo de 398 itens diferentes entre todas as linhas de dormitórios fabricados, totalizando-se 7.029 itens danificados somente no mês de janeiro de 2004. A soma de $\mathrm{R} \$ 13.812,84$ (US\$ 4.604,28) corresponde aos custos para substituir um novo item ao cliente, não se incluindo, nesse valor, os custos de transportes pagos por clientes das diferentes cidades, Estados e até mesmo Países, o que não constitui objeto de estudo nesta pesquisa.

Com relação aos principais motivos por que os produtos retornam à empresa constam: peças quebradas, riscos nos produtos, matéria-prima com defeito e batida, entre outros danos ou erros como falta de peça, falta de ferragem, peça trocada, aspectos que revelam erro humano, ocasionado, talvez, pela inexistência da aplicação de Gestão de Qualidade. O total de 7.029 unidades representa a quantidade de peças danificadas, o que soma R $\$ 1.3812,84$ (US\$ 4.604,28). Porém, os itens mais relevantes que foram demonstrados graficamente somam 6.778 peças. A Figura 5 demonstra a afirmação feita anteriormente. 


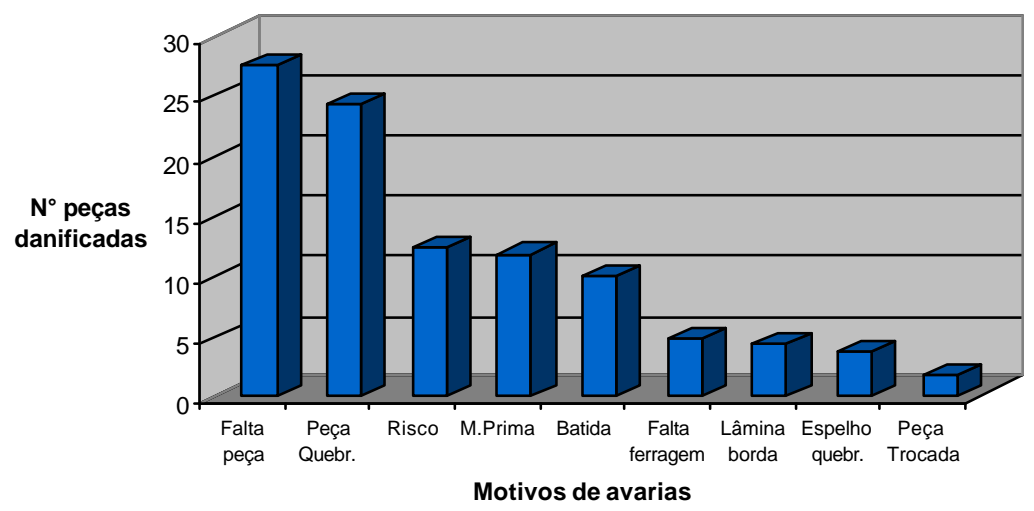

Figura 5: Assistência de produtos avariados por motivo no mês de janeiro de 2004.

Fonte: O autor

No mês de janeiro último, o peso total faturado carregado de produtos para diversas localidades foi de $15.510,64 \mathrm{~kg}$, enquanto o total de produtos avariados, em porcentagem, foi de $0,047 \%$. Num primeiro momento, os núme ros parecem revelar uma quantidade nãosignificativa, porém, em relação aos custos totais de produtos substitutos, tal total corresponde a R $\$ 13.812,84$ (US\$ 4.604,28), sem se mencionarem os custos de transporte, embalagem, tempo e insatisfação dos clientes.

O processo logístico é afetado por causas intensas que atuam permanentemente, resultando em produtos danificados. Essas causas estão relacionadas com o uso de equipamentos externos inadequados; falta de treinamento ou treinamento insuficiente para manusear os produtos; possibilidade de atendimento a certas solicitações de clientes o que acaba implicando mudanças contínuas na produção. Como a empresa utiliza equipamentos internos adequados à movimentação dos produtos e também possibilita treinamentos freqüentes para o seu quadro de colaboradores, presume-se que as causas de ocorrência de avarias dessa natureza são externas à empresa com mais freqüência do que internas.

Porém, o fato em questão não justifica o descaso por parte dos gerentes da empresa em análise devido às danificações nos produtos representarem menos de $1 \%$ do total carregado. Ressalta-se novamente que, em apenas um mês, os custos de reposição pela Assistência Técnica da empresa representaram $\mathrm{R} \$ 13.812,00$ (US\$ 4.604), valor que poderia ser investido em equipamentos, em infra-estrutura ou em treinamento interno e externo à fábrica, por exemplo.

Com relação aos produtos danificados da empresa moveleira da região norte, observou-se que, no ambiente interno da fábrica, há a preocupação constante com o controle da qualidade dos produtos e, principalmente, com o atendimento ao cliente no que tange às trocas, às substituições de produtos avariados por outros novos. Existe uma política interna da 
empresa em que o cliente é prioridade e onde se deve fazer com que o prazo de reposição dos bens danificados seja cumprido.

As principais causas de avarias, no caso específico dessa empresa última, dão-se com mais freqüência devido ao transporte, ao manuseio e armazenamento externos. Comprova-se, com isso, que no momento em que o produto sai da fábrica, ela não possui total controle do que está acontecendo com suas mercadorias. Para ilustrar a situação da empresa, no que tange a produtos avariados de maior frequiência, vale observar a Figura 6, o qual totaliza 2.815 unidades reposicionadas aos clientes.

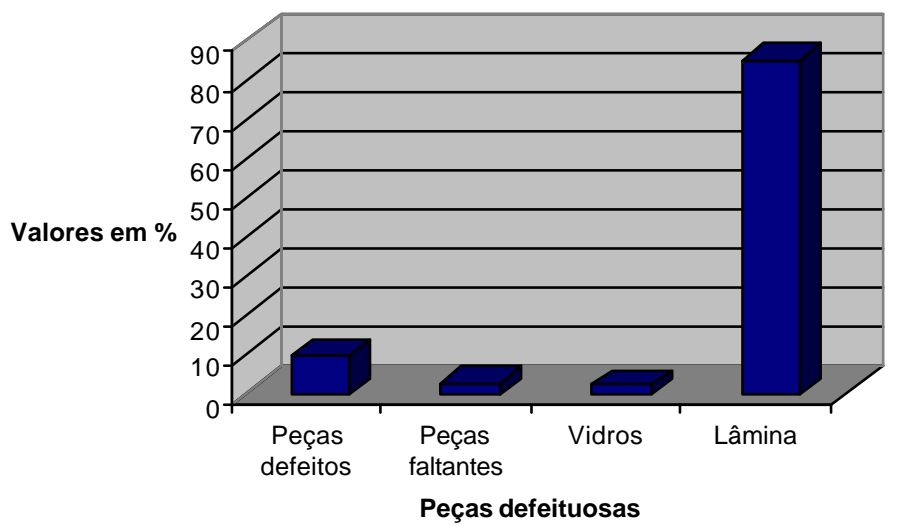

Figura 6: Principais motivos de avarias da empresa da região norte do mês de janeiro de 2004.

Fonte: O autor

A Figura 6 demonstra, grosso modo, num primeiro momento não se trata de uma quantidade significativa, prém com relação aos custos totais de produtos substitutos, tais danos correspondem a numerários relativamente expressivos para a empresa, considerando-se, principalmente, os seus poucos anos de existência no mercado e sua expansão nos mercados interno e externo. No entanto, existe a insatisfação dos clientes ao perceberem que o produto adquirido não possui a qualidade que esperavam, e que não se têm parâmetros para mensurar quanto em valores Reais uma empresa perde com insatisfações dessa natureza.

Percebe-se que a esta última possui um volume de produtos avariados relativamente inferior ao da empresa da região central o que se deve não somente ao conhecimento de essa fábrica possuir um volume de vendas maior, mas também pelo fato de que a empresa da região norte dispõe de um maior cuidado às embalagens protetoras.

\section{ROTEIRO DA METODOLOGIA APLICADA ÀS INDÚSTRIAS}

\section{MOVELEIRAS}


Uma possibilidade de reduzir essas variáveis que atuam de forma negativa no processo é a aplicação do Ciclo PDCA e Diagrama de Ishikawa sobre o processo conforme a Figura 7. Através desse esquema desenvolvido para amenizar as ocorrências de avarias nas indústrias, parte-se do seguinte: o processo inicia com a entrada da matéria-prima (chapas de compensado, ferramentas, tintas) que deve ser fornecida com qualidade para que o produto final tenha a qualidade primada pelos gestores. Para tal, a seleção de fornecedores eficientes e eficazes deve ser priorizado por parte da gerência responsável pelo fornecimento, uma vez que se utilize matéria-prima desqualificada, de nada adiantará adotar uma metodologia que vise amenizar falhas. Depois de inspecionado a matéria-prima, roda-se, a seguir, o Ciclo PDCA de controle de processo, o qual tem por objetivo obter um diferencial estratégico através do controle de todas as etapas que foram anteriormente planejadas, além de estabelecidas um padrão aceitável.

Assim, no PLANEJAMENTO (P), os gerentes do setor de logística, juntamente com alguns colaboradores, estabelecem-se as metas sobre os itens de controle, bem como a maneira para atingir as metas. É através de observações e da identificação do problema que se realiza a análise do processo para, após, então traçar um plano de ação. Nesse caso, devem-se determinar as metas e os caminhos para atingi-las no que se refere ao processo de transformação da matéria-prima em um produto manufaturado, incluindo a fase de embalamento e expedição do produto. Nesta fase de planejamento aborda-se também questões como treinamentos periódicos aos colaboradores que operam na transformação, embalagem e expedição dos produtos, pois é primordial que a empresa instigue aos colaboradores a maneira correta de proceder diante das tarefas a serem realizadas. Vale ressaltar que para que esse processo proceda de forma desejada as matérias-primas devem também ser de qualidade.

A EXECUÇÃO (E) é o momento de realizar as tarefas necessárias para a produção das mercadorias, tais como foram orientadas e previstas no planejamento. É primordial que haja treinamento do corpo de colaboradores das empresas (interno e externo) para executarem o trabalho proposto. É a fase em que procede também à coleta de dados. Então, observar se os colaboradores estão realmente aplicando aquilo que lhes fora passado no treinamento é imprescindível para que a transformação e embalagem da matéria-prima em produto final tenham a qualidade que fora estimada, além de observação se a movimentação interna à empresa está dentro das conformidades aceitáveis.

Após a etapa anterior, realiza-se a VERIFICAÇÃO (C) do processo a partir dos dados coletados na execução, comparando-a com o resultado no trabalho decorrente da fase de planejamento. Essa fase também é importante pela grande confusão que alguns fazem em 
distinguir quais os itens que devem ser verificados. Portanto, na fase de Planejamento $(\mathrm{P})$ já deverá constar qual é o padrão que a empresa estabelece como aceitável. A partir daí, realizase a verificação, analisando se os itens verificados estão dentro do que fora estabelecido ou não.

E, finalmente, ATUAÇÃO CORRETIVA (A), fase em que se detectam os desvios ocorridos no processo de fabricação e, neste caso, fazendo-se as devidas alterações para corrigir os erros para que o problema não incida com tanta freqüência. Porém, pode-se perceber que está tudo normal, ou seja, os procedimentos estão dentro do padrão estabelecido. Nesse caso, aconselha-se a manter os mesmos processos para que se tenha uma faixa padrão.

Após "rodar" o Ciclo PDCA, passa-se ao Diagrama de Ishikawa (Espinha de Peixe) para investir na continuidade do controle do processo, relacionando sua causa-efeito. Portanto, ao ocorrer um resultado (efeito) há um conjunto de causas (meios) que podem ter influenciado o processo a apresentar um resultado. Ao separar os fins dos meios, as pessoas que fazem parte da empresa terão maior facilidade em detectar os erros ou os desvios que causaram um resultado não-satisfatório. Dessa forma, foram divididas as principais atividades pertinentes ao processo de fabricação de móveis que poderão causar desvios, comprometendo o processo, conforme demonstrado na Figura 7. 
EMPRESA Ciclo PDCA

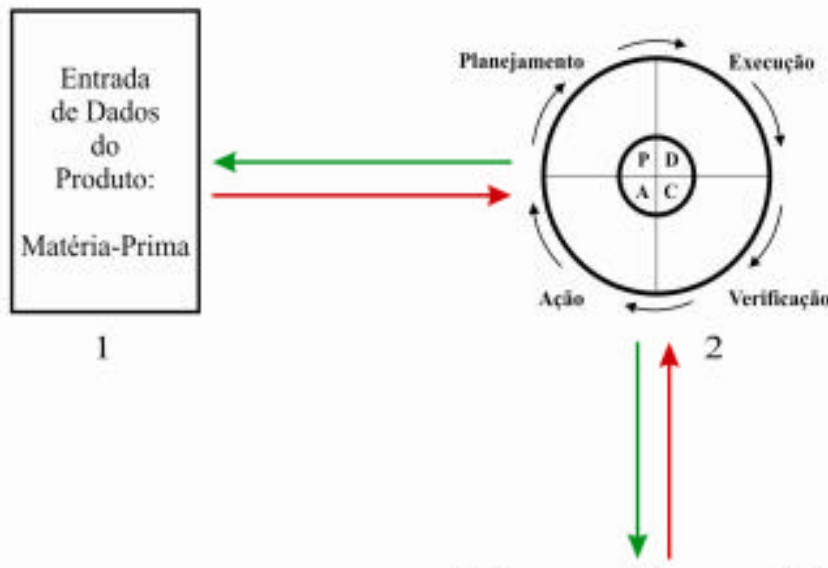

Diagrama Causa e Efeito

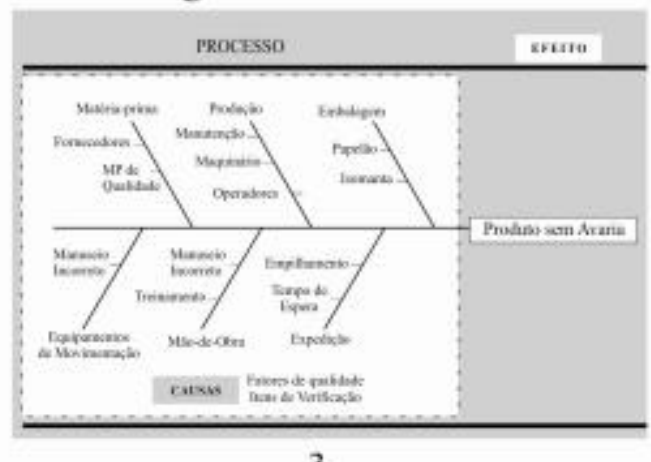

3

Figura 7: Controle do processo através do Ciclo PDCA e Diagrama de Ishikawa.

Fonte: O autor

Nesse sentido, cada item de verificação (matéria-prima, produção, embalagem, equipamentos, mão-de-obra, expedição) deverá ser analisado a fim de verificar se todo o processo está de acordo com a política de se obter qualidade superior, sendo estes itens de fácil inspeção também pelos próprios colaboradores. Ao detectar que um item de verificação não está conforme o estipulado para doter um produto de qualidade, retorna-se ao Ciclo PDCA para planejar, executar, verificar e tomar as ações corretivas novamente, pois muitas vezes pode-se traçar um Planejamento $(\mathrm{P})$ que não condiz com a capacidade da empresa, não podendo, portanto, ser atingido. Essa é, pois, uma ferramenta da Qualidade Total que proporciona subsídios para a verificação dos desvios, bem como permite averiguar quais as atitudes mais adequadas a serem desenvolvidas com vista a resolver ou a amenizar os problemas que, inevitavelmente, ocorrem, seja na linha de produção, seja na embalagem, no transporte, na armazenagem ou mesmo na montagem do móvel.

Ao propor esse roteiro para otimizar o processo logístico das empresas em questão, teve-se o seguinte resultado: a empresa de menor porte da região norte aceitou a possibilidade 
de aplicar uma ferramenta da Qualidade Total, pois a sua principal preocupação é atender de forma eficiente e eficaz os seus consumidores, estando em fase de adaptação, pois essa metodologia proposta exige por parte da gerência adaptações e explanações ao seu quadro de colaboradores, uma vez que quem utiliza esse processo são os mesmos, os quais convivem com as tarefas da fase de verificação. O processo de aprendizado e sensibilização está sendo realizado, em seguida aplicar-se-á o controle do processo por meio das ferramentas da qualidade total, sendo que nesta fase exigirá não só a ação dos colaboradores da empresa, e sim dos próprios gerentes, caracterizando-se uma ação em conjunto.

No momento de apresentar a proposta de melhoria à fábrica de maior porte localizada na região central do Estado, esta mencionou que já realiza controle de qualidade através de inspeções de amostra de produtos (aproximadamente a cada 10 produtos produzidos, verificase os itens estabelecidos), porém não foi adotado as ferramentas aqui sugeridas. Sobre as demais sugestões, a empresa já havia feito parcerias com lojistas há alguns anos atrás, mas houve uma certa resistência por parte dos prestadores de serviços dos principais lojistas da empresa, mesmo havendo uma queda significativa de produtos danificados.

Enfim, ao mencionar a importância de um produto ser entregue dentro dos padrões de qualidade e prazos combinados com o cliente, Dornier et al (2000, p. 211) ressalva que "a satisfação resulta quando a empresa ou produto atende a todo um conjunto de expectativas do cliente, tais como disponibilidade do produto, confiança na entrega, suporte e qualidade".

\section{CONSIDERAÇÕES FINAIS}

Após observações e análises comparativas entre as duas fábricas em estudo, chegou-se a algumas considerações diferenciadas sobre a atuação de uma e de outra no que concerne as causas do índice de produtos danificados, soluções e atitudes perante o consumidor lesado, providências a serem tomadas para que o mesmo erro não incida, entre outros, apesar das empresas fabricarem linhas de produtos semelhantes, mas possuírem realidades e visões um tanto antagônicas.

Com relação aos problemas de produtos avariados da fábrica da região central, deve-se reavaliar a possibilidade de adoção de uma nova embalagem de proteção interna. Essa deverá ser mais resistente em substituição da Isomanta já utilizada somente para os produtos mais frágeis como os espelhos, uma vez que a embalagem adotada pela empresa não oferece total proteção contra os impactos inevitáveis na movimentação da carga. A gramatura dos papelões utilizados é de baixa qualidade, devendo igualmente ser readequada para uma melhor proteção. 
De igual forma, é conveniente realizarem-se testes específicos dos produtos já embalados, através de equipamentos de choque e vibração, além de testar a resistência com relação ao peso que cada embalagem suporta nos paletes, a fim de se evitarem alterações das embalagens antes mesmo de elas saírem da expedição (ambiente interno). Salienta-se que ao existirem alterações das embalagens antes mesmo de elas saírem do ambiente interno, tais invólucros ficarão mais suscetíveis à ocorrência de danos, contribuindo, assim, para o aumento do índice de avarias nos produtos acabados.

Habitualmente, quando as mercadorias deixam o ambiente interno da fábrica, essa, por sua vez, não dispensa ao produto o mesmo controle que lhe dava em ambiente interno. Isso é retratado por ambas as empresas através das mercadorias danificadas, cujo dano fora provocado pelo descarregamento feito pelos colaboradores dos lojistas (principais clientes), armazenamento incorreto e montagem por pessoas sem qualificação, treinamentos. Para esse problema ser amenizado, seria prudente às empresas em questão desenvolverem parcerias com os lojistas, carregadores e montadores a fim de executarem treinamentos em conjunto. Após a etapa dos treinamentos, deve-se realizar um acompanhamento periódico a fim de avaliar os aspectos positivos e/ou negativos referentes à redução ou não do índice de produtos avariados.

Salienta-se que nenhuma das fábricas possui um canal de linha direta para o atendimento ao consumidor, como um sistema 0800, onde os consumidores finais possam ligar gratuitamente para as empresas a fim de opinar, criticar, sugerir. Essa também é uma forma de as empresas aproveitarem a oportunidade para absorver os dados dos consumidores que procuram as fábricas através da captação e reunião das informações, podendo formatar um banco de dados com questões de suma importância como a freqüência de compra dos consumidores, itens adquiridos, grau de satisfação, percepção de qualidade nos produtos, entre outros. Enfim, um canal de linha direta dessa natureza é uma realidade bastante próxima aos consumidores e muito utilizada por eles.

A justificativa da empresa da região norte em não ter linha direta gratuita é que ao observar danos ou na embalagem ou no produto, os lojistas entram em contato direto com a fábrica para substituir o produto. Agindo dessa forma, os clientes finais não chegam a receber nem a perceber danificações nos produtos. Porém, o mesmo não é verdadeiro na outra fábrica, uma vez que alguns clientes finais acabam recebendo os bens e percebendo neles avarias, causando-lhes insatisfação. Assim, os consumidores reclamam aos lojistas e esses, por sua vez, repassam os problemas para a fábrica. Nessa mesma fábrica, quando ocorrem reclamações, sugestões, críticas dos clientes, essas observações são feitas pelos próprios 
clientes aos lojistas ou aos representantes, os quais repassam essas informações à empresa. Em contrapartida, a organização fica dependente ou dos lojistas ou dos representantes, não tendo o conhecimento real do grau de satisfação dos clientes.

Para amenizar a ocorrência de avarias, é conveniente aplicar as ferramentas da Qualidade Total, conforme Figura 7, uma vez que a Qualidade Total constitui um meio de a empresa analisar todo seu processo, desde a fabricação até a expedição do produto no ambiente interno. Devido ao tempo em que as empresas desenvolvem suas atividades, por se considerar que existem ainda colaboradores da empresa que estão praticamente a seu lado, desde a sua abertura, acredita-se que o modo como a empresa executa as atividades seja a correta. No entanto, é fundamental proceder-se constantemente a análises e correções de itens que fogem do padrão estabelecido pelo Planejamento. Agindo dessa maneira, acredita-se ser possível amenizar as incidências de danos freqüentes ocorridos por vários motivos, pois eliminar totalmente a incidência de avarias é algo irreal, utópico. A discussão do assunto em capítulos anteriores demonstra que as principais causas de danos em produtos que comprometem a qualidade não dependem somente de fatores do ambiente interno, mas, principalmente, dos fatores que acontecem no ambiente externo às fábricas em estudo.

Com as considerações que encerram o estudo sobre a análise de falhas em um processo logístico devido à falta de um controle qualidade, espera-se ter contribuído para percepção de que não são apenas fatores externos à organização que incidem em danos, mas também a fatores internos a empresa, reconhecendo que a Qualidade Total é imprescindível para alinhar o processo logístico e, conseqüentemente, a satisfação do cliente em âmbito geral.

\section{REFERÊNCIAS}

ALMEIDA, Léo G. Qualidade: introdução a um processo de melhoria. Rio de Janeiro: Qualitymark, 1995.

BALLOU, Ronald H. Gerenciamento da cadeia de suprimentos: planejamento, organização e logística empresarial. 4 ed., Porto Alegre: Bookman, 2001.

Logística empresarial: transportes, administração de materiais e distribuição física. São Paulo: Atlas, 1993.

BARCANTE, Cesar L. Qualidade total: uma visão brasileira. Rio de Janeiro: Campus, 1998. 
BLANCHARD, Ken \& STONER, Jessé. The vision thing: without it you'll never be a worldclass organization. Leader to Leader, 2004. <http://pfdf.org/leaderbooks>. Acesso em: 18 abr. 2004.

BOWERSOX, Donald J., \& CLOSS, David J. Logística empresarial: o processo de integração da cadeia de suprimentos. São Paulo: Atlas, 2001.

CAMPOS, Vicente Falconi. TQC: controle da qualidade total (no estilo japonês). 7 ed., Rio de Janeiro: Bloch Ed., 1992.

CERVO, Amado Luiz \& BERVIAN, Pedro Alcino. Metodologia científica. 4 ed., São Paulo: Makron Books, 1996.

CHRISTOPHER, Martin. Logística e gerenciamento da cadeia de suprimentos: estratégias para a redução de custos e melhoria de serviços. São Paulo: Thomson Pioneira, 1997.

DORNIER, Philippe-Pierre et al. Logística e operações globais: textos e casos. São Paulo: Atlas, 2000.

DRUMMOND, Helga. Movimento pela qualidade: de que o gerenciamento de qualidade total realmente se trata. São Paulo: Littera Mundi, 1998.

HAMEL, Gary. Innovation as a deep capability. Leader to Leader, 2003. Disponível em: <http://www.pfdf.org/leaderbooks/121/winter2003/hamel.html>. Acesso em: 12 mai. 2004.

JURAN, J. M. A qualidade desde o projeto: os novos passos para o planejamento da qualidade em produtos e serviços. São Paulo: Pioneira Thomson Learnig, 2002.

JURAN, J.M. \& GRYNA, Frank M. Controle da qualidade: componentes básicos da função qualidade. São Paulo: McGraw-Hill/Makron, 1991.

MINTZBERG, Henry \& QUINN, James Brian. O processo da estratégia. 3 ed., Porto Alegre: Bookman, 2001.

OLIVEIRA, Otávio J. Gestão da qualidade: tópicos avançados. São Paulo: Pioneira Thomson Learning, 2004.

PORTER, Michael E. A vantagem competitiva das nações. 9 ed., Rio de Janeiro: Campus, 1989a.

Vantagem competitiva: criando e sustentando um desempenho superior. 20 ed., Rio de Janeiro: Campus, 1989b.

PREE, Max De. Creative leadership. Leader to Leader, 2001. Disponível em: <http://www.pfdf.org/leaderbooks/121/spring2001/depree.html>. Acesso em: 12 mai. 2004.

STONER, James A. F. R., \& FREEMAN, Edward. Administração. 5 ed., Rio de Janeiro: LTC; 1999. 
Artigo recebido em 08/01/2005 e aceito para publicação 15/06/05 